\title{
Letter to the Editor: Application of Haddon Matrix in Disaster Management: A New Window in Disaster Mitigation Risk
}

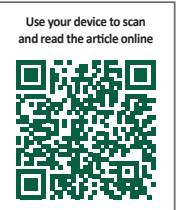

Citration Khorasani-Zavareh D, Nouri F, Sadeghi-Bazargani H. Application of Haddon Matrix in Disaster Management: A New Window in Disaster Mitigation Risk. Health in Emergencies and Disasters Quarterly. 2018; 4(1):3-4. http://dx.doi.org/10.32598/ hdq.4.1.3

doi: : http://dx.doi.org/10.32598/hdq.4.1.3

\section{ABSTRACT}

In recent years, disaster management has been the focus of attention since disasters have been associated with huge destructions and consequences. Basically, disaster management techniques aim at the prevention and mitigation works as well as promotion of resilience.

Haddon's matrix was proposed as a conceptual model to understand the event and provide preventive measures in the field of injury prevention. This matrix is a combination of epidemiological triangle, including host, agent, and environmental factors at three levels of prevention, including pre-event, event, and post-event. In spite of frequent application of Haddon's strategies in prevention of various injuries; hitherto, application of Haddon matrix in disaster management has been rarely investigated. However, its potential capability for managing disasters calls for its further introduction which is the main focus of our study.

\section{Introduction}

isasters account as the main factor for mor$\mathbf{D}$ tality, morbidity, disability, destruction of infrastructures, and demolishing of the environment. In recent years, disasters have been associated with huge destructions and worse consequences, so disaster management has been drawn more attention with focus on prevention and mitigation works as well as promotion of resilience [1]. Adopting of "an all-hazard approach" in disaster management has paved the way to mitigate the risk of disasters, human casualties, and their economic and bio-environmental effects in demolishing the community infrastructure as [2]. Therefore, a wide variety of disaster management models, from traditional to systematic approach ones, have been proposed in disaster risk reduction [3].

\section{Haddon Matrix}

System approach in disaster management is a model which describes the relationship of risk assessment and risk management so as to mitigate the effects of disasters [3]. However, this approach is in its first steps and not fully developed yet. In 1970, Dr. William Haddon proposed a conceptual model to understand the event and prevent injury based on a systematic prospective research through investigating the detection of countermeasures. Haddon's Matrix (HM) proposes a combination of epidemiological triangle (host, agent, and environmental factors) at three levels of prevention, including pre-event, event, and post-event. Moreover, his 10 famous strategies provide provisions for intervention and prevention of injury at three stages $[4,5]$.

His 10 strategies for injury prevention and control are as follows: 1. Prevent the hazard creation; 2. Minimize the amount of hazard; 3. Prevent the release of the agent; 4. Modify the release of the hazard from its source; 5 . Separate the hazard in time or place from what is to be protected; 6. Separate the hazard with physical barrier; 7. Minimize damage by modification of supra- and infra-structures; 8 . Increase resilience of the structure or host to be protected; 9. Provide emergency response already done; 10. Provide emergent care and rehabilitate what has been damaged [6].

Most injuries generates from sequential and continuous events rather than discrete ones. The Matrix provides a clear image from a complexity of the event, which is very useful to simplify the event and make it more understandable. Thus it creates innovative ideas about prevention and management of the disaster $[7,8]$. 
HM was employed in a wide range of injury prevention incidents like traffic crashes, civil/domestic fires, suicide and falls. It has also been used as a qualitative content analysis tool in injury research methodology [9]. However, it is important to note that despite wide use of HM in injury field, its beneficial role in disaster management is still unrecognized. For example in man-made disasters, human agent could be those variables which facilitate release of energy and accelerates the damage, or hinders the process response to emergency situations. Application of HM can identify influence of socio-physical factors in creation of risk, occurrence of the event (expel of the energy), and health-related responses in emergencies [10].

\section{Discussion and Conclusion}

Despite frequent application of Haddon's 10 strategies in prevention of various injuries, its application in disaster management has not been much investigated yet. A study in Queensland used HM to investigate the interaction of risk factors of flood to discover possible solutions for decreasing its mortality [11]. Moreover, HM was also applied to analyze bomb explosion in London transport system in 2005 [10]. Regarding all-hazard approach in disaster management, the role of Haddon's 10 strategy in preventing mortality and morbidity of the future disasters is not clear yet $[11,12]$. These strategies may provide prevention and mitigation of the damage and protect the community/ population against disaster and help rehabilitation $[10,11]$. However, its application should be further explored in detail. Accordingly authors suggest its application in disaster risk reduction in future research studies.

\footnotetext{
Davoud Khorasani-Zavareh ${ }^{1,2}$ (D), Fatemeh Nouri ${ }^{2 *}$ (D), Homayoun Sadeghi-Bazargani ${ }^{3}$

1. Safety Promotion and Injury Prevention Research Center, Shahid Beheshti University of Medical Sciences, Tehran, Iran.

2. Department of Health in Emergencies and Disasters, School of Public Health and Safety, Shahid Beheshti University of Medical Sciences, Tehran, Iran.

3. Road Traffic Injury Research Center, Tabriz University of Medical Sciences, Tabriz, Iran.
}

\section{* Corresponding Author:}

Fatemeh Nouri, PhD Candidate

Address: Department of Health in Emergencies and Disasters, School of Public Health and Safety, Shahid Beheshti University of Medical

Sciences, Tehran, Iran.

E-mail:f_nouri85@yahoo.com

\section{References}

[1] Arora R, Arora P. Disaster management: Medical preparedness, response and homeland security. Wallingford, Oxfordshire: CABI; 2013.

[2] Coppola DP. Introduction to international disaster management. Amesterdam: Elsevier; 2006.

[3] Asghar S, Alahakoon D, Churilov L. A comprehensive conceptual model for disaster management. Journal of Humanitarian Assistance. 2006; 1360(0222):1-15.

[4] Williams AF. The Haddon matrix: Its contribution to injury prevention and control. Paper presented at: $3^{\text {rd }}$ National Conference on Injury Prevention and Control. 9-12 May 1999; Brisbane, Queensland.

[5] Kuendig H. Empty glasses and broken bones: Epidemiological studies on alcohol and injuries treated at an emergency department in Switzerland. Rockefellersalen, Nobels väg: Institutionen för folkhälsovetenskap/Department of Public Health Sciences; 2009.

[6] Peck MD, Kruger GE, van der Merwe AE, Godakumbura W, Oen IM, Swart D, et al. Burns and injuries from non-electric-appliance fires in low-and middle-income countries: Part II. A strategy for intervention using the Haddon Matrix. Burns. 2008; 34(3):312-9. [DOI:10.1016/j.burns.2007.08.009] [PMID]

[7] Eckerman I. Chemical industry and public health: Bhopal as an example. Västra Frölunda, Sweden: Nordiska hälsovårdshögskolan; 2001.

[8] Runyan CW. Using the Haddon matrix: Introducing the third dimension. Injury Prevention. 2015; 21(2):126-30. [DOI:10.1136/ ip.4.4.302rep] [PMID]

[9] Deljavan R, Sadeghi-Bazargani H, Fouladi N, Arshi S, Mohammadi R. Application of Haddon's matrix in qualitative research methodology: An experience in burns epidemiology. International Journal of General Medicine. 2012; 5:621-7. [PMID] [PMCID]

[10] Arnold JL. The 2005 London bombings and the Haddon matrix. Prehospital and Disaster Medicine. 2005; 20(5):278-81. [DOI:10.1017/S1049023X00002715] [PMID]

[11] Zhong S, Clark M, Hou XY, Zang YL, FitzGerald G. 2010-2011 Queensland floods: Using Haddon's Matrix to define and categorise public safety strategies. Emergency Medicine Australasia. 2013; 25(4):345-52. [DOI:10.1111/1742-6723.12097] [PMID]

[12] Barnett DJ, Balicer RD, Blodgett D, Fews AL, Parker CL, Links JM. The application of the Haddon matrix to public health readiness and response planning. Environmental Health Perspectives. 2005; 113(5):561-6. [DOI:10.1289/ehp.7491] [PMID] [PMCID] 